\title{
Length of melatonin exposure and onset of ovarian activity in anoestrous ewes
}

\author{
R. Nowak* and R. G. Rodway \\ Department of Animal Physiology \& Nutrition, University of Leeds, Leeds LS2 9JT, U.K.
}

\begin{abstract}
Summary. Adult anoestrous ewes $(\mathrm{N}=30)$ were given intravaginal Silastic implants containing melatonin or empty implants $(\mathrm{N}=7$ ) during mid-anoestrus (4 July). Implants were removed 16 days later (Group 1), 36 days later (Group 2) or 93 days later (Group 3). Blood samples were taken twice weekly for progesterone assay to monitor onset of ovarian activity. The percentage of ewes in each group showing early onset of ovarian cyclicity was significantly correlated with length of exposure to melatonin.
\end{abstract}

\section{Introduction}

The onset of ovarian activity in the anoestrous ewe in response to short days (see Hafez, 1952) or to the rhythmic or continuous administration of exogenous melatonin (Kennaway et al., 1982; Nett \& Niswender, 1982; Arendt et al., 1983; Nowak \& Rodway, 1985) characteristically occurs some 8-10 weeks after initial exposure to the stimulant. In these previous studies short photoperiod or melatonin administration was continued until ovarian activity began. It is not known, therefore, to what extent the inductive effects of melatonin are dependent on its continued presence throughout this latent period. Fairly regular periods of sexual activity interspersed with anoestrous periods are seen in ewes maintained in uniform photoperiod or continuous light for long periods of time (Radford, 1961; Smith, 1967; Ducker et al., 1973), indicating that short photoperiods are not an absolute requirement for the expression of reproductive competence.

We have previously demonstrated (Nowak \& Rodway, 1985) that continuous administration of melatonin by intravaginal implants can substitute for short days to induce the onset of ovarian activity in the adult ewe. In these experiments the response time was approximately 8 weeks and the melatonin implants were left in place until after ovulation had occurred. In the work reported here we have examined the effect of removing the melatonin implants at various times before the onset of ovulation to determine whether exposure to melatonin for the whole duration of the latent period was necessary to induce or maintain subsequent ovarian activity.

\section{Materials and Methods}

Seasonally anoestrous Mule ewes, maintained under natural photoperiod from birth, were weaned from their lambs on 26 June and divided into four treatment groups such that the mean bodyweight of ewes in each group was approximately equal. On 4 July 23 ewes received $30 \mathrm{~cm}$ Silastic intravaginal implants of melatonin (Nowak \& Rodway, 1985). Melatonin implants were prepared from Silastic medical grade tubing (o.d. $0 \cdot 24 \mathrm{~cm}$, i.d. $0 \cdot 16 \mathrm{~cm}$; Dow Corning Corporation, Midland, MI, U.S.A.) packed with crystalline melatonin (Sigma, Poole, U.K.; $8.5 \mathrm{mg} / \mathrm{cm}$ tubing). Implants were held in place in the vagina by polyurethane sponges. The 7 control ewes received empty implants (Group C). Melatonin implants were removed 16 days later (20 July, Group 1, $N=8$ ), 36 days later $(9$ August, Group 2, $\mathrm{N}=8$ ) or 93 days later ( 5 October, Group 3, $\mathrm{N}=7$ ). The empty implants were also removed on 5 October. Throughout the experiment rams were rigorously excluded from the surrounding area.

*Present address: Department of Physiology, Monash University, Clayton, Victoria 3168, Australia. 
Blood samples were taken by jugular venepuncture twice weekly throughout the experiment, and plasma was stored at $-20^{\circ} \mathrm{C}$ until assayed for progesterone as described previously (Nowak \& Rodway, 1985). Inter- and intraassay variations were $10.9 \%$ and $16.1 \%$. The sensitivity of the assay was $1.1 \mathrm{nmol} / \mathrm{l}$. Progesterone concentrations greater than $2 \mathrm{nmol} / \mathrm{l}$ for two consecutive samples were taken to indicate the onset of ovarian activity. For farm management purposes the experiment was terminated on 8 October.

\section{Results}

The incidence of ovarian activity was significantly advanced in Group 3 ewes (Fig. 1): 4 of the 5 $(80 \%)$ had started cycling by 8 October, with a mean response time from implantation to first ovulation of 9.1 weeks. At implant removal, 2 ewes of this group were found to have lost the melatonin part of their implants and have, therefore, been excluded from the results. By 8 October only 1 of 7 control ewes $(14 \%)$ had started to cycle $(4 / 5$ vs $1 / 7, P<0.05$, Fisher test). The proportions of ewes in Groups 1 and 2 that began to cycle before 8 October were $25 \%(2 / 8)$ and $50 \%$

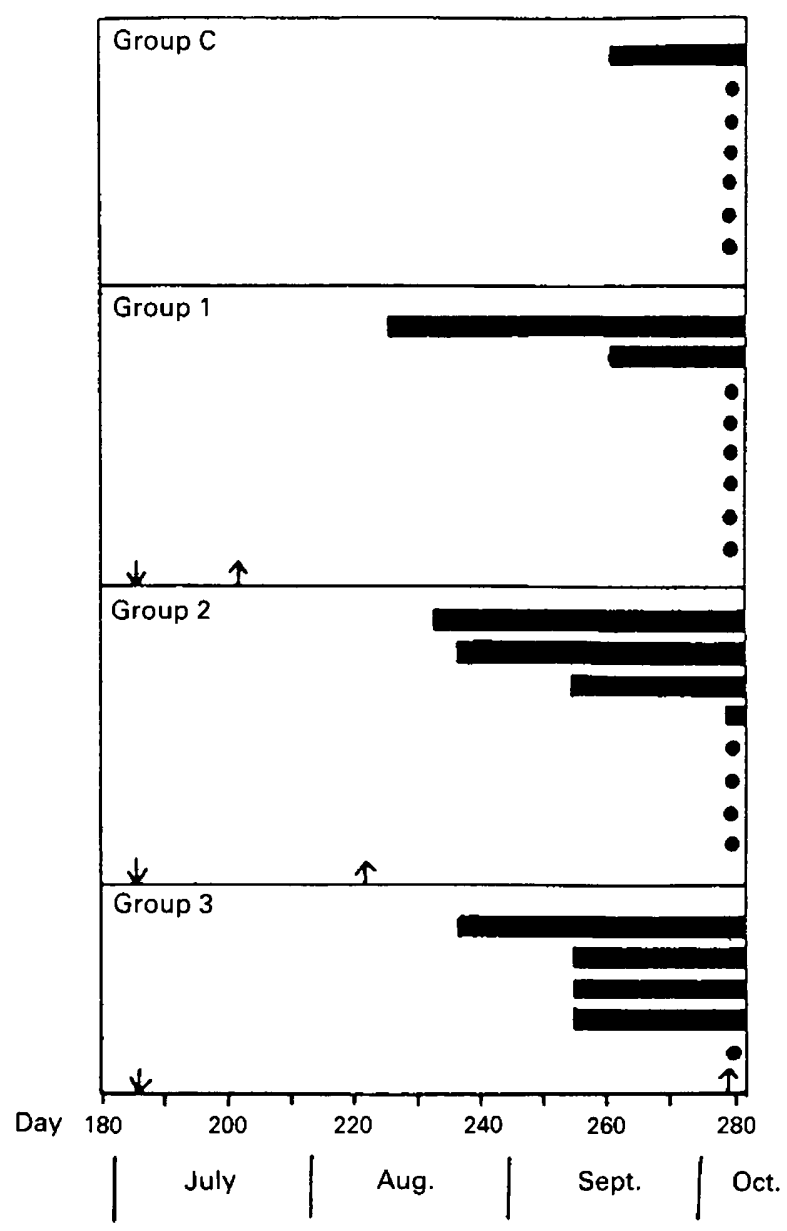

Fig. 1. Occurrence of ovarian cycles (solid bars) in control and melatonin-implanted ewes: $\downarrow$, time of implant insertion; $\uparrow$, time of implant removal. Solid circles $(\bullet)$ indicate ewes that had not started cycling by 8 October. Day $1=1$ January. 


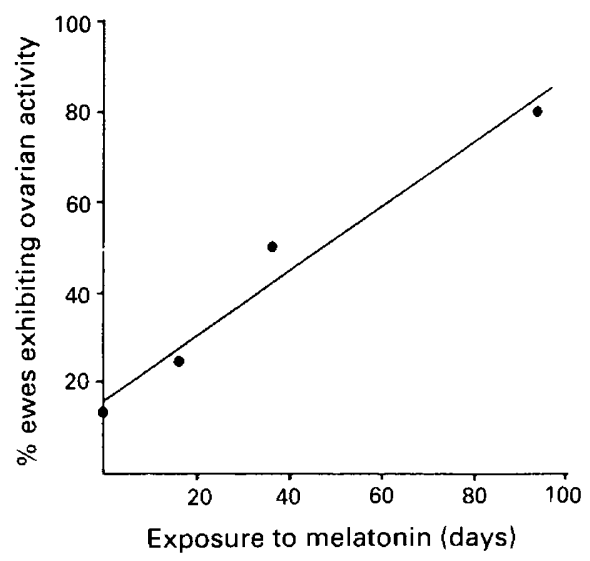

Fig. 2. Regression of percentage ewes showing early ovarian activity (cycling by 8 October) on the duration of exposure to exogenous melatonin: $y=16+0.7 x(r=0.98)$.

(4/8) respectively. Regression of the percentage of ewes cycling before 8 October on the duration of exposure to exogenous melatonin yielded a correlation coefficient $(r)$ of $0.98(P<0.01$, Fig. 2$)$.

Plasma progesterone profiles of control and melatonin-treated animals are shown in Fig. 3. Those ewes in Groups 2 and 3 that began cycling early had apparently normal ovarian cycles in terms of cycle length and plasma progesterone values, but 3 of the animals in Group 1 which were exposed to melatonin for only 16 days showed evidence of very short luteal phases with abnormally low concentrations of progesterone. These ewes were not considered to be cycling as their progesterone concentrations did not exceed $2 \mathrm{nmol} / \mathrm{l}$.

\section{Discussion}

In accordance with earlier findings (Nowak \& Rodway, 1985) the administration of melatonin via vaginal implants from July until October advanced the onset of ovarian activity. There was a significant correlation between the percentage of ewes exhibiting ovarian activity by 8 October and the length of melatonin exposure, such that as length of exposure increased the number of ewes responding increased. The results indicate that there is a considerable degree of variation between ewes in the duration of exposure to melatonin required to elicit a short-day response. There was, however, little difference between groups in the timing of the first ovulation indicating that the same $8-10$-week latent period is required regardless of whether or not the ewe is able to respond to a very short period of melatonin exposure.

This delay is similar to that found previously in ewes given melatonin by similar intravaginal implants (Nowak \& Rodway, 1985) or in subcutaneous Silastic packets or orally (English et al., 1986). Preliminary trials suggest also that increasing the dose of melatonin will not shorten this latent period (R. Nowak \& R. G. Rodway, unpublished observations). Very similar latent periods are seen when ewes are subjected to short photoperiods during anoestrus (Hafez, 1952; Newton \& Betts, 1972; English et al., 1986), although it does appear that the length of the latent period varies according to the abruptness of the shortening of the photoperiod and the time of year at which it is applied (Ducker \& Bowman, 1970a, b). However, in many of these experiments rams were used to detect oestrus and this almost certainly shortened the response time.

Progesterone profiles of those ewes given short-duration melatonin exposure suggest that there was a high incidence of long follicular phases and in several ewes luteal function was impaired, with progesterone values much lower than those seen in Group 3 ewes which had received melatonin for 


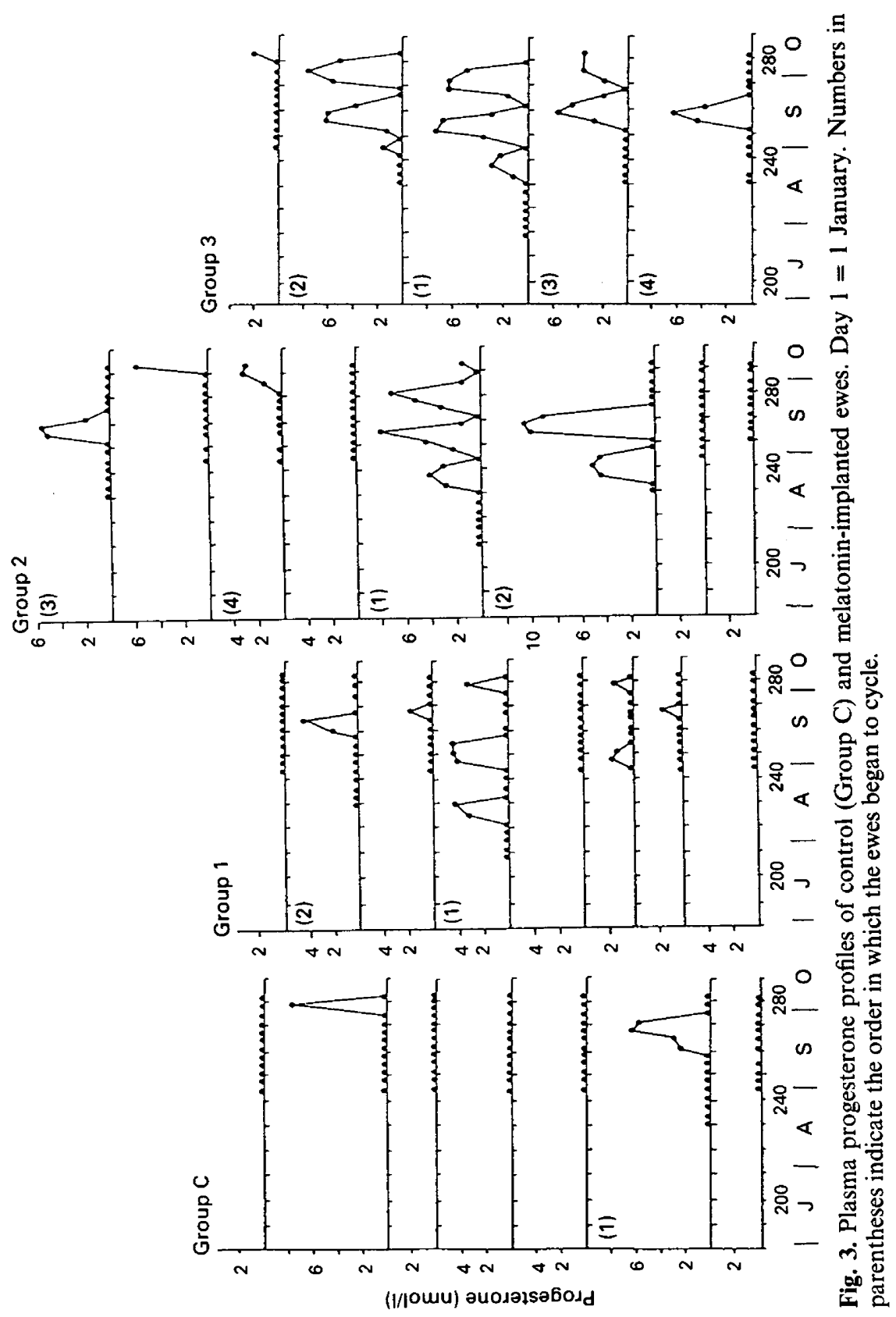


the full period. Similar abnormal cycles with isolated luteal phases, multiple short luteal phases and early return to anoestrus have been reported previously in lambs exposed to brief periods of short days during the summer (Foster, 1983). Unfortunately we were unable to continue sampling the ewes in the present experiment to determine whether the return to anoestrus was advanced, although unpublished studies from this Department suggest that ewes in which breeding season has been advanced with melatonin do show an early return to anoestrus.

We conclude that, although some ewes are able to respond to a very short period of melatonin exposure, a period of at least 36 days is required to obtain normal ovarian cyclicity in most of the ewes.

We thank Dr G. S. Pope, Shinfield, Reading, for the gift of progesterone antiserum.

\section{References}

Arendt, J., Symons, A.M., Laud, C.A. \& Pryde, S.J. (1983) Melatonin can induce the early onset of the breeding season in ewes. J. Endocr. 97, 395-400.

Ducker, M.J. \& Bowman, J.C. (1970a) Photoperiodism in the ewe. 2. The effects of various patterns of decreasing daylength on the onset of oestrus in Clun Forest ewes. Animal Production 12, 115-123.

Ducker, M.J. \& Bowman, J.C. (1970b) Photoperiodism in the ewe. 4. A note on the effect on onset of oestrus in Clun Forest ewes of applying the same decrease in daylength at two different times of year. Animal Production 12, 513-516.

Ducker, M.J., Bowman, J.C. \& Temple, A. (1973) The effect of constant photoperiod on the expression of oestrus in the ewe. J. Reprod. Fert., Suppl. 19, $143-150$.

English, J., Poulton, A.L., Arendt, J. \& Symons, A.M. (1986) A comparison of the efficacy of melatonin treatment in advancing oestrus in the ewe. $J$. Reprod. Fert. 77, 321-327.

Foster, D.L. (1983) Photoperiod and sexual maturation of the female lamb: early exposure to short days perturbs estradiol feedback inhibition of luteinizing hormone secretion and produces abnormal ovarian cycles. Endocrinology 112, 11-17.
Hafez, E.S.E. (1952) Studies on the breeding season and reproduction of the ewe. J. agric. Sci., Camb. 42, 189-265.

Kennaway, D.J., Gilmore, T.A. \& Seamark, R.F. (1982) Effect of melatonin feeding on serum prolactin and gonadotropin levels and the onset of seasonal estrus activity in sheep. Endocrinology 110, 1766-1772.

Nett, T.M. \& Niswender, G.D. (1982) Influence of exogenous melatonin on seasonality of reproduction in sheep. Theriogenology 17, 645-653.

Newton, J.E. \& Betts, J.E. (1972) A comparison between the effects of various photoperiods on the reproductive performance of Scottish half-bred ewes. $J$. agric. Sci., Camb. 78, 425-433.

Nowak, R. \& Rodway, R.G. (1985) Effects of intravaginal implants of melatonin on the onset of ovarian activity in adult and prepubertal ewes. J. Reprod. Fert. 74, 287-293.

Radford, H.M. (1961) Photoperiodism and sexual activity in Merino ewes. Aust. J. agric. Res. 12, $139-145$.

Smith, I.D. (1967) The effect of constant long daily photoperiod upon the onset of puberty in ewes. $J$. agric., Sci. Camb. 69, 43-45.

Received 18 November 1986 